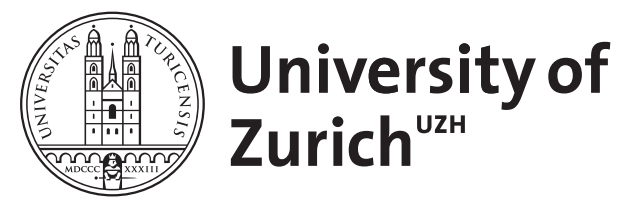

\title{
Stability of personality traits in adulthood
}

Allemand, Mathias ; Gruenenfelder-Steiger, Andrea E ; Hill, Patrick L

\begin{abstract}
Stability represents a fundamental concept in developmental theory and research. In this article we give an overview of recent work on personality traits and their stability in adulthood. First, we define personality traits and stability. Second, we present empirical evidence supporting change and stability of personality traits across the adult years with respect to conceptually and statistically different forms of stability. Third, we describe mechanisms and processes that enable trait stability. Finally, we discuss implications of trait stability for theory, research, and application.
\end{abstract}

DOI: https://doi.org/10.1024/1662-9647/a000080

Posted at the Zurich Open Repository and Archive, University of Zurich ZORA URL: https://doi.org/10.5167/uzh-84313

Journal Article

Accepted Version

Originally published at:

Allemand, Mathias; Gruenenfelder-Steiger, Andrea E; Hill, Patrick L (2013). Stability of personality traits in adulthood. GeroPsych, 26(1):5-13.

DOI: https://doi.org/10.1024/1662-9647/a000080 
Running head: STABILITY OF PERSONALITY

Stability of Personality Traits in Adulthood: Mechanisms and Implications

\author{
Mathias Allemand ${ }^{1}$, Andrea E. Steiger ${ }^{1}$, \& Patrick L. Hill ${ }^{2}$ \\ ${ }^{1}$ University of Zurich \\ ${ }^{2}$ University of Illinois at Urbana-Champaign
}

\begin{abstract}
Accepted for Publication in
The Journal of Gerontopsychology and Geriatric Psychiatry
\end{abstract}

Preparation of this article was supported, in part, by Swiss National Science Foundation (SNSF) grant no. CRSI11_130432/1.

Correspondence concerning this article should be addressed to Mathias Allemand, University of Zurich, Department of Psychology, Binzmühlestrasse 14/24, CH-8050 Zurich, Switzerland (e-mail: m.allemand@psychologie.uzh.ch). 


\begin{abstract}
Stability represents a fundamental concept in developmental theory and research. In this article we give an overview of recent work on personality traits and their stability in adulthood. First, we define personality traits and stability. Second, we present empirical evidence supporting change and stability of personality traits across the adult years with respect to conceptually and statistically different forms of stability. Third, we describe mechanisms and processes that enable trait stability. Finally, we discuss implications of trait stability for theory, research, and application.
\end{abstract}

KEYWORDS: Personality; traits; stability; change; adulthood 


\section{Introduction}

The goal of this article is to give an overview of recent work on personality trait stability in adulthood. Understanding personality traits and their stability is important for several reasons. First, research demonstrates the ability of personality traits to predict a variety of important life outcomes such as mortality, divorce, and occupational attainment (Roberts, Kuncel, Shiner, Caspi, \& Goldberg, 2007). Therefore, understanding stability may be essential in such areas as maintaining health and success in work and marriage. Second, because stability of behavior is an important manifestation of personality, identifying mechanisms of stability and conditions under which stability is most pronounced is an important way to understand personality itself (Gallager, Fleeson, \& Hoyle, 2011). Third, understanding stability is important for the assessment of personality traits over time, as an adequate use of time intervals is needed to accurately capture systematic trait development. Fourth, interventions to change behavior will be more effective if based on an accurate account of the stability of traits. Knowledge of the circumstances under which trait behaviors are more or less likely will make changing them easier.

The first part of this article refers to the definition of personality traits and stability. In the second part we briefly describe current research on trait stability in adulthood. In the third part, we discuss some mechanisms that might be responsible for trait stability and describe some conditions and processes related to the maintenance of stability. In the last part of this article, we discuss potential implications of trait stability and then suggest some ideas for future research. Whereas most previous reviews tend to describe personality trait development with a focus on change (e.g., Allemand \& Lehmann, 2012; Caspi, Roberts, \& Shiner, 2005; Roberts, Wood, \& Caspi, 2008; McAdams \& Olson, 2010), this article places a greater emphasis on stability of traits and processes underlying stability. It also differs from previous reviews by using a slightly different categorization of stability. Finally, in clear contrast to other reviews, we suggest some specific ideas about intervening on personality stability. 


\section{Definition of Personality Traits and Stability}

Personality traits are defined as relatively enduring patterns of behavior, thought, and feeling that are relatively consistent across a wide variety of situations and contexts (Roberts, 2009). Traits describe the most basic and general dimensions upon which individuals are typically perceived to differ. These individual differences are often organized within the conceptual framework of the Big Five (John, Naumann, \& Soto, 2008) or Five-Factor model (McCrae \& Costa, 2008) and include five broad traits: neuroticism, extraversion, openness to experience, agreeableness, and conscientiousness. Briefly, neuroticism, or conversely, emotional stability, contrasts even-temperedness with the experience of anxiety, worry, anger, and depression. Extraversion refers to individual differences in the propensity to be sociable, active, assertive, and experience positive affect. Openness to experience refers to individual differences in the proneness to be original, complex, creative, and open to new ideas. Agreeableness refers to traits that reflect individual differences in the propensity to be altruistic, trusting, modest, and warm. Finally, conscientiousness reflects the propensity to be self-controlled, task- and goal-directed, planful, and rule following.

In general, personality traits are thought to be relatively stable over time, and thus they are not assumed to change at a rapid rate but rather reflect slow processes (Roberts \& Jackson, 2008). Unlike traits, states reflect dynamic processes of personality that show temporary changes in response to internal aspects such as motives and goals and external situations such as stress in a given situation (Fleeson, 2001; Hooker \& McAdams, 2003). States reflect the ways how individuals think, feel, or behave in a given situation. They are transient and involve change and variability over short periods of time. In other words, a person with a high average level of emotional stability may still demonstrate a different behavior in a given situation such as on a day when he or she faces a difficult challenge. Typically though, an individual thinks, feels, or behaves consistent with that person's average standing on the trait-level. We come back to the discussion of states later in this article when 
discussing mechanisms of stability. In sum, personality traits are conceptualized as enduring tendencies to behave, think, and feel, whereas states reflect temporary changes in behavior, cognition, and emotions.

Stability is defined in several ways. For this article we focus on five conceptually and statistically different forms of stability (see Caspi, 1998; Caspi \& Roberts, 2001 for other forms). First, mean-level stability implies that the average level of a personality trait remain stable over time and/or across different ages. Second, differential or rank-order stability implies that individuals maintain their relative standing on a trait dimension relative to others over time. Third, stability of the variance implies that individual differences in a trait dimension remain stable over time and/or across different ages, even though the mean levels and rank order are unstable. Fourth, structural stability refers to the stability of the patterns of covariation among traits, or items on a personality scale. High structural stability implies that the associations between the traits are stable over time and/or across different ages. Fifth, individual differences in stability refer to the fact that although the average level of a personality trait remains stable over time, not every individual demonstrate the same amount of stability. Some individuals may increase, whereas others decrease over time. This perspective holds that personality stability is itself an individual-differences variable. In sum, there are several conceptually and statistically distinct ways of framing and answering questions about the stability of personality traits.

\section{Stability of Personality Traits}

Empirical evidence suggests that both change and stability describe personality trait development across adulthood depending partly on the form of stability one considers (Caspi \& Roberts, 2001; Roberts et al., 2008). Empirical evidence for personality trait change in adulthood comes from findings with respect to mean-levels and individual differences in development (e.g., Allemand, Zimprich, \& Hendriks, 2008; Donnellan \& Lucas, 2008; Lehmann, Denissen, Allemand, \& Penke, in press; Lucas \& Donnellan, 2011; Wortman, 
Lucas, \& Donnellan, in press). For example, in a very large cross-sectional sample of Internet users aged 10 to 65 ( $N=1,267,218)$, Soto, John, Gosling, and Potter (2011) found positive trends for mean levels of agreeableness and the self-discipline facet of conscientiousness. Neuroticism showed negative age trends across early adulthood and middle age, while extraversion demonstrated a small negative association during emerging adulthood and a relatively flat trend from young adulthood through middle age. Analysis of openness to experience revealed a positive age trend in mean levels across emerging adulthood that decelerates in middle age. A comprehensive meta-analytic review of longitudinal studies demonstrates systematic age-related mean-level changes in personality traits at various ages across adulthood (Roberts, Walton, \& Viechtbauer, 2006). The big picture that evidenced from cross-sectional and longitudinal studies on stability of the Big Five indicates that individuals tend to become more agreeable and conscientious and less neurotic with age. Whereas extraversion is rather stable in adulthood, openness to experience tends to increase in early adulthood and shows moderate decreases in older age. Compared to younger ages, less is known about personality development in old and very old age. Available findings, however, suggest that personality trait development continues in old age (e.g., Allemand, Zimprich, \& Martin, 2008; Mõttus, Johnson, \& Deary, 2012). In general, personality changes are small in magnitude with respect to specific age periods. However, most of the Big Five traits demonstrated changes close to one standard deviation across the lifespan, which is typically considered as a large effect in psychology (Roberts et al., 2006).

These longitudinal trends even appear to have downstream effects on more specific trait dimensions. One case example involves forgivingness, or the dispositional tendency to forgive others, tends to be highest among agreeable and emotionally stable individuals (e.g., Balliet, 2010; Mullet, Neto, \& Rivière, 2005). Following the mean-level trends for agreeableness and emotional stability to increase in adulthood, multiple studies have reported a positive age trend for forgivingness during adulthood as well (see Allemand \& Steiner, 
2012; Hill, Allemand, \& Heffernan, 2012 for reviews). Indeed, research has provided evidence that the age effects for forgivingness can be partially explained by the age trends in these two Big Five traits, even though forgivingness is empirically separable from both higher-order traits (Steiner, Allemand, \& McCullough, 2012).

Similarly, studies have begun to investigate how patterns of stability and change in the higher-order Big Five traits coincide with the patterns for the lower-order traits, or facets, that comprise those domains. In general, this literature points to the tendency for facets to evidence similar levels of change to their respective Big Five traits, and yet this may not always be the case (Jackson et al., 2009; Soto \& John, 2012; Terracciano, McCrae, Brant, \& Costa, 2005). For instance, while conscientiousness as a whole tends to increase during adulthood, its facets differ with respect to the magnitude of this increase (e.g., impulse control shows a stronger age effect than industriousness, defined as a tendency toward being hardworking and diligent), and some facets even fail to demonstrate any mean-level change (e.g., orderliness) (Jackson et al., 2009).

Although empirical evidence supports the claim that personality continues to change in adulthood at the mean levels, there is also growing evidence for reliable individual differences in personality development across the adult years (e.g., Mroczek \& Spiro, 2003; Roberts \& Mroczek, 2008; Specht, Egloff, \& Schmuckle, 2011). This implies that some individuals change while others remain stable. These systematic deviations from the sample mean-levels suggest variability in the degree and direction of personality trait change. In this context, individual differences in change reflect the plurality and diversity of life experiences individuals can encounter in adulthood such as getting married or getting fired from job, retirement, or physical and cognitive decline in later adulthood. Specific life events might lead to different personality trajectories for individuals, which can help to explain the variability in development. For example, men who get remarried in middle adulthood show a decline in neuroticism (Mroczek \& Spiro, 2003). Other studies, however, reported only 
modest effects of life events on the levels of personality traits in midlife (Costa, Herbst, McCrae, \& Siegler, 2000). In sum, although systematic mean-level changes were found, some individuals remain they same through the adult years.

Empirical evidence for personality trait stability in adulthood comes from findings with respect to differential stability, stability of variance, and structural stability (e.g., Ferguson, 2010; Mõttus et al., 2012; Terracciano, Costa, \& McCrae, 2006; Zimprich, Allemand, \& Lachman, 2012). A large body of literature demonstrates increasing levels of differential stability across the adult years in terms of maintaining rank-order stability (Roberts \& DelVecchio, 2000). More specifically, estimates of mean population test-retest correlation coefficients showed that the overall trait stability increased 0.54 during the college years to 0.64 at age 30 and then reached a plateau around 0.74 between ages 50 and 70 . Moreover, differential stability did not vary markedly across the Big Five traits, or across assessment method or gender.

With respect to stability of variance, empirical evidence suggests that trait variances remain relatively stable over time and/or across different ages (e.g., Allemand, Zimprich, \& Hendriks, 2008; McCrae, 1993). That is, individual differences in the traits seem consistent. Finally, cross-sectional and longitudinal research demonstrates relatively high levels of structural stability in traits over time and/or across different ages (e.g., Allemand, Zimprich, \& Hertzog, 2007; Mõttus et al., 2012; Zimprich et al., 2012). However, it is not clear whether the factorial structure of traits remains stable in old age. There is preliminary evidence for structural change in the Big Five traits in old age (Allemand, Zimprich, \& Martin, 2008). Investigations of structural stability often include the testing of measurement equivalence (e.g., Allemand et al., 2007; Jackson et al., 2009; Zimprich et al., 2012). This important issue in developmental psychometrics touches the question of whether psychological constructs are comparable across different age groups or across measurement occasions. Frequently, in developmental studies it is implicitly assumed that the measurement process of constructs is 
similar across age and/or measurement occasions. However, there may be age differences in the conceptual frame of reference in interpreting or reacting to a given item of a questionnaire or to stimulus material in experimental studies, thus altering the way the latent construct underlying the item or stimulus is measured. Therefore, the process of measurement equivalence establishes that the same construct is being measured in the same way on different occasions and/or different age groups. It is considered as a prerequisite for making meaningful inferences about stability of a construct over time and ages.

In sum, previous research demonstrates mean-level change in personality traits in adulthood and at the same time relatively high levels of stability with respect to rank-order, variance, and the structure. More important, significant individual differences in change and stability were found across the adult years, implying that not every individual develops like the normative trend. More research is needed on personality stability in old and very old age.

\section{Mechanisms of Trait Stability}

Adulthood is characterized by a multitude of life experiences and environmental influences that might have an impact on the stability of personality traits. Indeed, research demonstrates mean-level changes in traits as a result of specific life experiences such as military service (Jackson, Thoemmes, Jonkmann, Lüdtke, \& Trautwein, 2012), and the transition from high school to university and adult life (Bleidorn, in press; Lüdtke, Roberts, Trautwein, \& Nagy, 2011). While major life events can change personality (Specht et al., 2011), these effects may be relatively modest in magnitude (Costa et al., 2000). Moreover, research found that perceiving stressful life events as turning points or lessons learned is related to changes in some personality traits in midlife (Sutin, Costa, Wethington, \& Eaton, 2010). There is also emerging evidence that personality traits can be experimentally manipulated and changed with direct or indirect interventions over relatively short periods of time (e.g., De Fruyt, Van Leeuwen, Bagby, Rolland, \& Rouillon, 2006). For example, a recent study demonstrates that cognitive training with the intent to change cognitive skills showed an 
increase in openness over time in a group of older adults (Jackson, Hill, Payne, Roberts, \& Stine-Morrow, 2012). However, as this study exemplifies, most of these interventions were not designed with the intent of manipulating personality traits, which as we note below should serve as an important direction for future research.

Given all these life changes that occur during adulthood, and their capability to influence personality, it is particularly noteworthy then that such high levels of trait stability characterize this developmental period. This naturally leads to the question of which causes and processes might be responsible for stability and its maintenance. The mechanisms for trait stability can be organized into categories such as environmental factors, biological or person factors, and the complex interplay between individuals and their environments (see Caspi \& Roberts, 2001; Roberts et al., 2008 for reviews). For example, although the degree to which certain genes are expressed may vary across adulthood, the genotype itself is invariant and relatively unchanging and thus may contribute to trait stability over time. In addition, personality traits may show stability because the environment remains stable, or more precisely, because individuals perceive their environment in consistent ways. Research suggests that trait stability typically results from both genetic and environmental factors (e.g., Bleidorn, Kandler, Riemann, Angleitner, \& Spinath, 2009; Kandler, Bleidorn, Riemann, Spinath, Thiel, \& Angleitner, 2010).

Several complicated interactions between individuals and situations may contribute to trait stability as well (Fraley \& Roberts, 2005; Roberts et al., 2008). For example, the personality profile one presents may elicit particular responses from the social environment that can promote personality stability. Extraverted individuals may evoke more pleasant and supportive responses from their peers that contribute to more positive social interactions, which, in turn, reinforce the tendency to be sociable. In addition, personality traits shape how individuals perceive, interpret, and respond to social situations. A consistent interpretation of situations over time may promote stability in personality traits. Moreover, it is assumed that 
individuals actively select or create social roles and environments that are consistent with their personality or they change the environments to better fit with their personality. It should be noted that the mechanisms underlying personality stability might change themselves across adulthood. For example, active selection of environments appears to be linked to individuals' control potential which changes across the lifespan (Heckhausen, Wrosch, \& Schulz, 2010). Moreover, physical and cognitive decline may limit older adults to select environments.

An interesting point of departure for studying processes that enable trait stability is based on the distinction between traits and states. As mentioned before, states typically demonstrate high levels of variability and temporary changes over short periods of time in response to internal and external factors. States are thought to act as the intermediate between the environment, biological factors, and personality traits. Roberts and Jackson (2008) proposed a model that account for the multiple pathways through which environment and biological factors could shape personality traits and their stability over time (see also Fraley \& Roberts, 2005). For example, the environment can influence whether and how traits are manifested in a given situation. In addition, individuals with certain personality profiles will select into specific environments, thus in turn also predicting how traits are manifested. Both processes in tandem then can determine whether an individual exhibits greater or less trait stability, by virtue of presenting similar or different personality states.

How individuals think, feel, and behave in a given situation can be either consistent or inconsistent with their average trait-level. Therefore, the consistency between traits and their state manifestations might reflect a specific mechanism that supports trait stability. A recent study found empirical support for this idea with respect to rank-order stability (Gallagher et al., 2011). Briefly, these researchers tested the hypothesis that behaviors that run counter from an individual's average trait-level (contra-trait behaviors) demand more effort, or self-control, than habitual behaviors (trait-typical behaviors). In other words, a highly neurotic person may find it more difficult to perform emotionally stable behaviors than neurotic behaviors. There 
are several reasons why contra-trait behaviors may be more effortful than trait-typical behavior (cf. Gallagher et al., 2011). First, contra-trait behaviors may cause psychological conflicts for the individual because they are not consistent with the habitual trait-related patterns of behavior. Second, habitual and well-learned behaviors demand less attention, less conscious cognition, and less effort than nonhabitual behaviors and they are shown more frequently than unfamiliar behaviors. Inhibiting trait-typical behaviors and generating contratrait behaviors thus require more self-control than simply behaving as usual. As a consequence, individuals will likely enact habitual behaviors, which in turn further promotes trait stability.

This line of reasoning is similar to Caspi and Moffitt's (1993) accentuation hypothesis. This hypothesis suggests that individual differences in personality exert their strongest influence on responses when individuals are confronted with unpredictable situations. Given that behaving in ways that correspond to the average trait-level requires little mental energy, individuals choose behaviors that match their personality traits (trait-typical behaviors) when uncertain about the given situation. In other words, when there are no pressures to behave differently or even information on how to do so, individuals should be most prone to exhibit habitual behaviors and routines. Individuals may also show habitual behaviors when encounter new situations because familiar responses may be incompatible with the situation, thus producing stress, which then becomes associated with the new stimulus. These processes stabilize traits over time.

In sum, there are several mechanisms related to environmental and biological or person factors and individual by environment interactions that may explain the high levels of stability of personality traits in adulthood. These mechanisms may explain stability with respect to different forms. 
Trait stability in adulthood has several implications for theory, research, and application. We focus on five implications. One important implication from a functional perspective is that trait stability may serve different functions. On the one hand, stability functions to benefit the individual. For example, being stable provides a sense of sameness and continuity, which is central to having a sense of identity (Erikson, 1959). In other words, to view oneself as a stable person across different contexts and situations, and to see one's environment as relatively controllable and with similar expectations satisfies the need for orientation and control. Having some routine and control may help individuals to avoid stress or negative states and to gain pleasure. On the other hand, stability also functions to benefit not only the individual but also his or her social environment in the sense that it structures and reduces the complexity of social interactions or interactions between individuals and situations. As such, it increases the predictability and continuity of behaviors so that individuals can better anticipate each other's actions. By contrast, a lack of stability increases the unpredictability of behavior. For this reason, personality instability often is an indicator of personality disorders.

The second implication refers to the fact that although personality is relatively stable across the adult years, not every individual show the same level of stability, as individual differences in stability do exist. This suggests that different individuals follow different paths of development in adulthood. Helson and Srivastava (2001) identified four different paths for adult development based on the standing on two variables: environmental mastery and personal growth. Environmental mastery refers to the ability to control and manage one's environment, and one's efficacy in choosing environments that suit one's goals and needs; individuals high on personal growth though place emphasis on continued development across the lifespan, which occurs by virtue of seeking new experiences (Ryff, 1989). According to Helson and Srivastava (2001), adults may emphasize environmental mastery ("conservers"), personal growth ("seekers"), both (“achievers"), or neither (“depleted”). Pertaining to the 
current discussion, it is possible that personality trait change is more adaptive for those adults who seek out new experiences because this allows them to better adapt to new opportunities and situations. By contrast, for other individuals stability seems likely better so that they perceive greater consistency and control.

Future research may examine whether some personality profiles or some specific personality patterns promote higher levels of stability compared to others. For example, individuals with higher levels of cognitive and behavioral rigidity or inflexibility and closemindedness might be less willing and able to adjust to new situations and thus prefer low levels of stimulation and novelty and the preservation of beliefs, attitudes, and behaviors (Schultz \& Searleman, 2002). In contrast, motivational factors such as willingness to change may play an important role as well. For example, individuals with higher levels of active and intentional involvement in changing and developing their person (or growth initiative, Robitschek, 1998) may be more open for changing their personality.

The third implication refers to mechanisms of trait stability. Several efforts have been made to identify mechanisms of trait stability and conditions that enable or maintain stability and this knowledge will help in advancing theory. In this article, we made the claim that a focus on state manifestations of traits is an interesting avenue for research on trait stability, because states are more susceptible and malleable than traits. As mentioned before, a trait is a predisposition to act in the same way in a wide range of situations. However, individuals may differ in how they think, feel, and behave in similar situations. In other words, some individuals may take different actions at different times in effectively the same situations, while other individuals have a restricted behavioral repertoire and thus show the same traittypical behaviors in similar situations. As such, behavior variability reflects an individual difference variable that can vary over time and/or across different ages (e.g., Fleeson, 2001; Noftle \& Fleeson, 2010). 
Future research may investigate whether high versus low intraindividual variability in behavior, thought, and feeling enable trait stability and/or facilitate developmental change. For example, high levels of variability may help individuals to adapt to new situations and challenges with flexibility and thus support trait change, whereas low variation may corroborate stability. Some support for this idea comes from the cognitive aging literature. A recent study demonstrates that intraindividual variability in performing cognitive tasks predicted the amount of changes in cognitive ability three years later in a group of older adults (Bielak, Hultsch, Strauss, MacDonald, \& Hunter, 2010). Such attempts are in line with a broader goal of developing a unifying theoretical personality framework that account for traits, states, and their interplay over time and ages.

The fourth implication is to explicitly consider different forms of stability in the assessment of personality, as some forms are more related to stability of personality traits in adulthood, whereas others suggest that although traits are relatively stable, they change and are responsive to life experiences and interventions. Moreover, as previous work is largely based on self-reports, it is important to use multiple methods for studying personality stability such as self- and observer-reports and to examine their convergence over time and/or across different age groups (e.g., Jackson et al., 2009; McCrae et al., 2004). It is possible that selfand observer-reports lead to differential results such that individuals perceive themselves as highly consistent across situations and over time, whereas observer-reports suggest change or vice versa. For example, self-ratings of young adult newlywed couples demonstrated significant increases in conscientiousness and agreeableness and a decline in neuroticism over two years (Watson \& Humrichouse, 2006). By contrast, spouse ratings yielded a different pattern with decreases in all Big Five except for neuroticism over time. At the same time rank-order stability was consistently high and did not differ across self- and spouse ratings. Such results support the notion that personality development is typically multidirectional. 
There is also a need for objective, behavioral assessments of traits over time and/or across different ages. For example, it would be interesting to assess individual differences in predictable and unpredictable situations in order to examine individual differences in the stability of trait-typical behavior. Future research is needed both to connect behaviors and state manifestations to traits, as well as to make sure the same behaviors mean the same thing across the lifespan in the sense that they are measurement equivalent. Both points would be needed before looking into personality stability from a behavioral perspective.

Fifth, from an applied perspective, trait stability has clear implications for personality interventions in several ways. Knowledge about trait stability and their mechanisms and conditions will help researchers develop tools that facilitate individuals in their developmental decisions, in age-graded transitions and social roles in adulthood, at turning points, major life events, or in matters of self-development. In addition, the typically high levels of stability underscore how difficult it will be to enact personality trait change. However, it also speaks to the promise of these interventions (e.g., De Fruyt et al., 2006; Jackson, Hill et al., 2012). If personality is stable, then any real changes that result from an intervention will likely have long-term effects. Therefore, studies of stability point both to the relative difficulty and reward of personality interventions.

Though researchers have discussed the importance of intervening to affect personality change, the topic of stability interventions has received little attention, despite the potential benefits of promoting trait stability. For example, research suggests that individuals are able to perceive trait change and that those perceptions of change show some correspondence with actual change (Robins, Noftle, Trzesniewski, \& Roberts, 2005). But perceptions of trait change with respect to the individual or his or her environment can be stressful for some individuals. The same can be true for the experience of massive undesired environmental changes. For example, a major reorganization in a business reflects such an environmental change. Processes of reorganization are often accompanied by reductions in staff and 
resources, new training programs, new organizational functions, and enlargement of scope of functions. Such fundamental organizational changes may produce feelings of insecurity and fears about the future and stress for some individuals, while it may enable changes especially for those individuals, who were unsatisfied with their current job or function. Long-term experiences of environmental changes and lack of control may affect some individuals, resulting in limitations of activity and participation. Intervening to promote stability may prove most adaptive during times of large-scale life changes, such as a massive reorganization at work or other difficult life experiences that may lead to losing control, orientation, and autonomy. In a similar vein, old age reflects an exemplar period in the lifespan that is associated with increased loss in control and autonomy as well as physical and cognitive decline. Promoting stability during these periods of change can be beneficial, because it helps individuals to retain a consistent and coherent picture of themselves despite of external (and internal) changes.

Such an intervention would focus on the stabilization of personality by means of inducing maintenance processes. An initial point of such interventions would be to describe causes and consequences of instability (or change) in the individual and to develop active exercises to stabilize personality. For example, individuals may need to be taught how their personality repertoire fits within the new environmental structure. That way, they do not feel the need to change, and they learn to retain their dispositions through tumultuous periods. Stability interventions may focus on influencing personality from the top-down by directly addressing traits, or from the bottom-up by manipulating state manifestations. In either case, their usefulness is necessarily dependent on the context, in that stability may or may not be a desired outcome in a given situation. Moreover, such interventions may influence multiple forms of stability at once. We know that the idea of intervening on the stability of personality is rather provocative in the light of current discussions emphasizing the changeability and plasticity of personality across the entire lifespan into old age (e.g., Allemand \& Lehmann, 
2012; Caspi et al., 2005; Roberts et al., 2008; McAdams \& Olson, 2010). In our view, such interventions would advance our knowledge about trait stability.

\section{Conclusion}

The study of personality traits and their stability is an important issue in personality and developmental science. First, personality traits are enduring characteristics that describe individual differences in behavioral, cognitive, and emotional patterns. Several conceptually and statistically distinct forms define stability. Second, current research on trait stability in adulthood suggests both change and stability depending partly on the forms of stability one considers. However, research on personality stability in old and very old age is clearly underrepresented in the literature. Third, different environmental, biological and person factors and their interactions might be responsible for the high levels of stability of personality traits in adulthood. One important approach to further investigate mechanisms of stability is to focus on the state manifestations of personality traits, and thus the stabilizing process mechanisms. Finally, high levels of personality trait stability have several implications for theory, research, and application. In particular, we suggest that promoting stability may prove adaptive when helping individuals dealing with changes in their lives. 


\section{References}

Allemand, M., \& Lehmann, R. (2012). Personality development and aging. In V. S. Ramachandran (Eds.), Encyclopedia of human behavior (pp. 74-81). San Diego, CA: Elsevier.

Allemand, M., \& Steiner, M. (2012). Situation-specific forgiveness and dispositional forgiveness: A lifespan development perspective. In E. Kahls \& J. Maes (Eds.), Justice psychology and conflicts: Theoretical and empirical contributions (pp. 361-375). New York: Springer.

Allemand, M., Zimprich, D., \& Hendriks, A. A. J. (2008). Age differences in five personality domains across the lifespan. Developmental Psychology, 44, 758-770.

Allemand, M., Zimprich, D., \& Hertzog, C. (2007). Cross-sectional age differences and longitudinal age changes in personality in middle adulthood and old age. Journal of Personality, 75, 323-358.

Allemand, M., Zimprich, D., \& Martin, M. (2008). Long-term correlated changes in personality traits in old age. Psychology and Aging, 23, 545-557.

Balliet, D. (2010). Conscientiousness and forgivingness: A meta-analysis. Personality and Individual Differences, 48, 259-263.

Bleidorn, W. (in press). Hitting the road to adulthood: Short-term personality development during a major life transition. Personality and Social Psychology Bulletin.

Bleidorn, W., Kandler, C., Riemann, R., Angleitner, A., \& Spinath, F. (2009). Patterns and sources of adult personality development: Growth curve analyses of the NEO-PI-R scales in a longitudinal twin study. Journal of Personality and Social Psychology, 97, 142-155.

Bielak, A. A., Hultsch, D. F., Strauss, E., MacDonald, S. W., \& Hunter, M. A. (2010). Intraindividual variability is related to cognitive change in older adults: Evidence for within-person coupling. Psychology and Aging, 25, 575-586. 
Caspi, A. (1998). Personality development across the life course. In W. Damon \& N. Eisenberg (Eds.), Handbook of child psychology: Vol. 3. Social, emotional, and personality development (5th ed., pp. 311-388). New York: Wiley.

Caspi, A., \& Moffitt, T. E. (1993). When do individual differences matter? A paradoxical theory of personality coherence. Psychological Inquiry, 4, 247-271.

Caspi, A., \& Roberts, B. W. (2001). Personality development across the life course: The argument for change and continuity. Psychological Inquiry, 12, 49-66.

Caspi, A., Roberts, B. W., \& Shiner, R. L. (2005). Personality development: Stability and change. Annual Review of Psychology, 56, 453-484.

Costa, P. T., Jr., Herbst, J. H., McCrae, R. R., \& Siegler, I. C. (2000). Personality at midlife: Stability, intrinsic motivation, and responses to life events. Assessment, 7, 365-378.

De Fruyt, F., Van Leeuwen, K. G., Bagby, R. M., Rolland, J. P., \& Rouillon, F. (2006). Assessing and interpreting personality change and continuity in patients treated for major depression. Psychological Assessment, 18, 71-80.

Donnellan, M. B., \& Lucas, R. E. (2008). Age differences in the Big Five across the life span: Evidence from two national samples. Psychology and Aging, 23, 558-566.

Erikson, E. H. (1959). Identity and the life cycle. New York: International Universities Press. Ferguson, C. J. (2010). A meta-analysis of normal and disordered personality across the lifespan. Journal of Personality and Social Psychology, 98, 659-667.

Fleeson, W. (2001). Towards a structure- and process-integrated view of personality: Traits as density distributions of states. Journal of Personality and Social Psychology, 80, 1011-1021.

Fraley, R. C., \& Roberts, B. W. (2005). Patterns of continuity: A dynamic model for conceptualizing the stability of individual differences in psychological constructs across the life course. Psychological Review, 112, 60-74. 
Gallagher, P., Fleeson, W., \& Hoyle, R. H. (2011). A self-regulatory mechanism for personality trait stability: Contra-trait effort. Social Psychological and Personality Science, 2, 335-342.

Heckhausen, J., Wrosch, C., \& Schulz, R. (2010). A motivational theory of lifespan development. Psychological Review, 117, 32-60.

Helson, R., \& Srivastava, S. (2001). Three paths of adult development: Conservers, seekers, and achievers. Journal of Personality and Social Psychology, 80, 995-1010.

Hill, P. L., Allemand, M., \& Heffernan, M. E. (2012). Placing dispositional forgiveness within theories of adult personality development. Submitted for publication.

Hooker, K., \& McAdams, D. P. (2003). Personality reconsidered: A new agenda for aging research. The Journals of Gerontology, Series B: Psychological Sciences and Social Sciences, 58B, 296-304.

Jackson, J. J., Bogg, T., Walton, K., Wood, D., Harms, P. D., Lodi-Smith, J. L., \& Roberts, B. W. (2009). Not all conscientiousness scales change alike: A multi-method, multisample study of age differences in the facets of conscientiousness. Journal of Personality and Social Psychology, 96, 446-459.

Jackson, J. J., Hill, P. L., Roberts, B. W., Payne, B. R., \& Stine-Morrow, E. A. L. (2012). Can an old dog learn (and want to experience) new tricks? Cognitive training increases openness to experiences in older adults. Psychology and Aging 27, 286-292.

Jackson, J. J., Thoemmes, F., Jonkmann, K., Lüdtke, O., \& Trautwein, U. (2012). Military training and personality trait development: Does the military make the man or does the man make the military? Psychological Science, 23, 270-277.

John, O. P., Naumann, L. P., \& Soto, C. J. (2008). Paradigm shift to the integrative Big Five trait taxonomy: History, measurement, and conceptual issues. In O. P. John, R. W. Robins, \& L. A. Pervin (Eds.), Handbook of personality: Theory and research (3rd ed., pp. 114-158). New York, NY: Guilford Press. 
Kandler, C., Bleidorn, W., Riemann, R., Spinath, F. M., Thiel, W., \& Angleitner, A. (2010). Sources of cumulative continuity in personality: A longitudinal multiple-rater twin study. Journal of Personality and Social Psychology, 98, 995-1008.

Lehmann, R., Denissen, J. J. A., Allemand, M., \& Penke, L. (in press). Age and gender differences in motivational manifestations of the Big Five from age 16 to 60. Developmental Psychology.

Lucas, R. E., \& Donnellan, M. B. (2011). Personality development across the life span: Longitudinal analyses with a national sample from Germany. Journal of Personality and Social Psychology, 101, 847-861.

Lüdtke, O., Roberts, B., Trautwein, U., \& Nagy, G. (2011). A random walk down university avenue: Life paths, life events, and personality trait change at the transition to university. Journal of Personality and Social Psychology, 101, 620-637.

McAdams, D. P., \& Olson, B. (2010). Personality development: Continuity and change over the life course. Annual Review of Psychology, 61, 517-542.

McCrae, R. R. (1993). Moderated analyses of longitudinal personality stability. Journal of Personality and Social Psychology, 65, 577-585.

McCrae, R. R., \& Costa, P. T., Jr. (2008). The Five-Factor theory of personality. In O. P. John, R. W. Robins, \& L. A. Pervin (Eds.), Handbook of personality: Theory and research (3rd ed., pp. 159-181). New York, NY: Guilford Press.

McCrae, R. R., Costa, P. T. Jr., Hrebickova, M., Urbanek, T., Martin, T. A., Oryol, V. E., Rukavishnikov, A. A., \& Senin, I. G. (2004). Age differences in personality traits across cultures: self-report and observer perspectives. European Journal of Personality, 18, 143-157.

Mõttus, R., Johnson, W., \& Deary, I. J. (2012). Personality traits in old age: Measurement and rank-order stability, and some mean-level change. Psychology and Aging, 27, 243249. 
Mroczek, D. K., \& Spiro, A., III. (2003). Modeling intraindividual change in personality traits: Findings from the normative aging study. The Journals of Gerontology, Series B: Psychological Sciences and Social Sciences, 58B, 153-165.

Mullet, E., Neto, F., \& Rivière, S. (2005). Personality and its effects on resentment, revenge, forgiveness and on self-forgiveness. In E. L. Worthington, Jr. (Ed), Handbook of forgiveness (pp. 159-182). New York: Brunner-Routledge.

Noftle, E. E., \& Fleeson, W. (2010). Age differences in big five behavior averages and variabilities across the adult lifespan: Moving beyond retrospective, global summary accounts of personality. Psychology and Aging, 25, 95-107.

Roberts, B. W. (2009). Back to the future: Personality assessment and personality development. Journal of Research in Personality, 43, 137-145.

Roberts, B. W., \& DelVecchio, W., F. (2000). The rank-order consistency of personality traits from childhood to old age: A quantitative review of longitudinal studies. Psychological Bulletin, 126, 3-25.

Roberts, B. W., \& Jackson, J. J. (2008). Sociogenomic personality psychology. Journal of Personality, 76, 1523-1544.

Roberts, B. W., Kuncel, N., Shiner, R. N., Caspi, A., \& Goldberg, L. (2007). The power of personality: A comparative analysis of the predictive validity of personality traits, SES, and IQ. Perspectives in Psychological Science, 2, 313-345.

Roberts, B. W., \& Mroczek, D. K. (2008). Personality trait stability and change. Current Directions in Psychological Science, 17, 31-35.

Roberts, B. W., Walton, K., \& Viechtbauer, W. (2006). Patterns of mean-Level change in personality traits across the life course: A meta-analysis of longitudinal studies. Psychological Bulletin, 132, 1-25.

Roberts, B. W., Wood, D., \& Caspi, A. (2008). The development of personality traits in adulthood. In O. P. John, R. W. Robins, \& L. A. Pervin (Eds.), Handbook of 
personality: Theory and research (3rd ed., pp. 375-398). New York, NY: Guilford Press.

Robins, R. W., Noftle, E. E., Trzesniewski, K. H., \& Roberts, B. W. (2005). Do people know how their personality has changed? Correlates of perceived and actual personality change in young adulthood. Journal of Personality, 73, 489-521.

Robitschek, C. (1998). Personal growth initiative: The construct and its measure. Measurement and Evaluation in Counseling and Development, 30, 183-198.

Ryff, C. D. (1989). Happiness is everything, or is it? Explorations on the meaning of psychological well-being. Journal of Personality and Social Psychology, 57, 10691081.

Schultz, P. W., \& Searleman, A. (2002). Rigidity of thought and behavior: 100 years of research. Genetic, Social, and General Psychology Monographs, 128, 165-207.

Soto, C. J., \& John, O. P. (2012). Development of Big-Five domains and facets in adulthood: Mean-level age trends and broadly versus narrowly acting mechanisms. Journal of Personality, 80, 881-914.

Soto, C. J., John, O. P., Gosling, S. D., \& Potter, J. (2011). Age differences in personality traits from 10 to 65 : Big Five domains and facets in a large cross-sectional sample. Journal of Personality and Social Psychology, 100, 330-348.

Specht, J., Egloff, B., \& Schmukle, S. C. (2011). Stability and change of personality across the life course: The impact of age and major life events on mean-level and rank-order stability of the Big Five. Journal of Personality and Social Psychology, 101, 862-882.

Steiner, M., Allemand, M., \& McCullough, M. E. (2012). Do agreeableness and neuroticism explain age differences in the tendency to forgive others? Personality and Social Psychology Bulletin, 38, 441-453. 
Sutin, A. R., Costa, P. T. Jr., Wethington, E., \& Eaton, W. W. (2010). Turning points and lessons learned: Stressful life events and personality trait development across middle adulthood. Psychology and Aging, 25, 524-533.

Terracciano, A., Costa, P. T., Jr., \& McCrae, R. R. (2006). Personality plasticity after age 30. Personality and Social Psychology Bulletin, 32, 999-1009.

Terracciano, A., McCrae, R. R., Brant, L. J., \& Costa, P. T., Jr. (2005). Hierarchical linear modeling analyses of the NEO-PI-R Scales in the Baltimore Longitudinal Study of Aging. Psychology and Aging, 20, 493-506.

Watson, D., \& Humrichouse, J. (2006). Personality development in emerging adulthood: Integrating evidence from self-ratings and spouse ratings. Journal of Personality and Social Psychology, 91, 959-974.

Wortman, J., Lucas, R. E., \& Donnellan, M. B. (in press). Stability and change in the Big Five personality domains: Evidence from a longitudinal study of Australians. Psychology and Aging.

Zimprich, D., Allemand, M., \& Lachman, M. E. (2012). Factorial structure and age-related psychometrics of the MIDUS personality adjective items across the lifespan. Psychological Assessment, 24, 173-186. 